\title{
Another Relationship to Failure: Reflections on Beckett and Education
}

\section{AISLINN O'DONNELL}

Failure is seen as a problem in education. From failing schools, to failing students to rankings of universities, literacy or numeracy, the perception that one has failed to compete or to compare favourably with others has led to a series of policy initiatives internationally designed to ensure 'success for all'. But when success is measured in comparison with others or against benchmarks or standards, then it is impossible to see how all could be successful given the parameters laid down. What are the implications of a culture that values success and achievement? How difficult is it to become the kind of individual who is flourishing, autonomous and becomes 'all she can be', in particular under the precarious conditions of contemporary capitalism? Samuel Beckett was sceptical of the quest for progress, production and prestige. His philosophy invites another way of thinking about failure, not as something one is, but rather as something one does: the pain and fear of inadequacy that can mark educational relations and experiences is alleviated by a more renunciative, gentle philosophy of education. There are two interwoven strands in this article. One questions the emphasis on competition and achievement in contemporary education and explores its implications for our relationship to failure. The second, strongly influenced by Beckett, explores ways of reimagining our relationship to failure in such a way that allows us to reflect on what matters in life.

\section{DO I ASK TOO MUCH?}

Our ideas depend on dialogue with others, but it can be easy to forget their origins in those relationships that orient our intellectual lives. The articles by Caroline Wilson, Sharon Todd and Rachel Jones in this Special Issue serve as a reminder of the importance of acknowledging our relational origins and our debt to others, helping us become more attuned to the ways in which the genesis of ideas is often bound up with the lives of others, our interlocutors. This article was born in failure, the failure to have an idea, or 
more precisely the failure to generate an idea of which I could be named the sole progenitor. It began with conversations in a prison on Samuel Beckett and pedagogy, conversations that emerged from our classes in philosophy. This article is dedicated to the man, the student in my class, whose interest in Beckett and whose illuminating readings of his writings invited me to reimagine failure.

Given the manner in which many, though not all, of his characters display antipathy toward children, and, unlike Luisa Muraro (see Caroline Wilson, this issue), seem to be convinced that it would have been better to never have been born (but since one has been, one must persist), whilst evincing a committed incapacity to be in any ordinary sense 'productive citizens', the writings of Samuel Beckett might seem a peculiar choice when reflecting upon philosophy of education. Yet, if one wishes to look at the world through a different lens, through those occupying its underside or its outside, then Beckett helps one do so without condescension or pity. His writings prompt consideration of some of the ways in which humans are situated on a graduated scale of recognisable humanity, teaching us how to develop another relationship to failure. His views on success, prestige and failure are traced through the denizens and anti-heroes of his prose and plays. His characters tend not to have much understanding of what is even meant by a 'normal', flourishing human life. Says one his most infamous characters, Molloy, of manners, 'On this subject I had only negative and empirical notions, which means that I was in the dark, most of the time, and all the more completely as a lifetime of observations had left me doubting the possibility of systematic decorum, even within a limited area' (Beckett, 1979, p. 25). Slapstick and bawdy humour puncture the erudite witticisms of the so-called intellectuals and philosophers he portrays. In later writings, Beckett's images of the human become ever more subtractive, bare, intensive and generic, more like the wind or light, eliminating those all-toohuman attributes that serve not only to identify and classify, but also to distinguish us from one another: each one becomes utterly singular, in a way that resonates with some of the descriptions offered by Rebecca Adami and Sharon Todd in this issue. Characters, even those made manifest through ebbs of intensity and bare descriptions of movement and breath, are often absorbed with preoccupations, rituals and programmes that seem foreign to those of ordinary humans. At moments they experience delight in the world and even ecstasy; much of the time they simply go on, living lives that elude familiar forms of narrative or temporal structure. Yet a closer look at their practices, observations and questions pushes us to question the purported logic of our own regimes of living, and to pay more attention to our unruly minds. Beckett's works are difficult and their themes might seem foreign to the concerns of those of us who work in education, but they are instructive because of their contemplations upon the human condition and their reflections upon ethics.

It is seldom that one finds such characters being either judgemental or displaying too much concern about what others think of them. It is not difficult to find something liberating in this indifference, not to others per $s e$, but to what others make of us. Such indifference does not foreclose 
gestures of kindness or solidarity with others. Often Beckett's characters make clear our profound dependence on others, as well the difficulty of getting along: couples like Vladimir and Estragon, in Waiting for Godot (Beckett, 2006), or Mercier and Camier, in the novel of the same name (Beckett, 1994b), do not need to understand each other, or even have anything in common, to stick with one other. The apparent disregard for what is supposed to constitute a 'successful' human life can give consolation to those who feel cowed by the pressures of success, allowing a space for the rather basic question of 'why' to be asked-Why do I desire this? Why do I seek recognition from them? Why is my career so important? Why do I need to know this? When in Worstward Ho, Beckett writes, 'Ever tried. Ever failed. No matter. Try again. Fail again. Fail better' (1983, p. 7), this serves to comfort. The kindly 'No matter' does not allude to prospective success or achievement but rather seems to encourage: 'Don't worry', 'Keep going', 'Keep trying', 'On'. It is unsurprising that artists have been drawn to this phrase, and indeed toward the end of this article I will examine some of these practices. ${ }^{1}$

There are two interwoven strands in this article. One questions the emphasis on competition and achievement in contemporary education and its implications for our relationship to failure. The second, strongly influenced by Beckett, explores ways of reimagining our relationship to failure in such a way that allows us to reflect on what matters in life. ${ }^{2}$ We may come to wonder whether we ask too much of humanity and of education when faced with images of mastery, autonomy, competition, potential, competence, flourishing and perfection that continue to inform philosophical principles that underpin educational practice. Christine Winter, Rebecca Adami, and Caroline Wilson, in particular, underline the corrosive effects of such aspirations. It may be wiser, as Sharon Todd suggests in Toward an Imperfect Education: Facing Humanity, Rethinking Cosmopolitanism that we temper our expectations of what education might achieve, and likewise to blunt and diminish those ambitions that tend to be most bolstered by a culture of competitiveness and standards that is, de facto, cultivated in many educational systems. Education cannot serve as the solution to society's ills and failures. Throughout his writings, one of Beckett's targets is education. The educational endeavour is often provocatively described as an exercise of relative futility, which offers, nonetheless, a form of distraction and an occasionally pleasant, occasionally taxing, way of passing time. In The Unnameable, the voice, Worm, seems confused by this practice, failing to grasp what the purpose of such an activity might be, although it seems nonetheless to have left its mark, for good or ill.

What puzzles me is the thought of being indebted for this information to persons with whom I can never have been in contact. Can it be innate knowledge? Like that of good and evil. This seems improbable to me. But what they were most determined for me to swallow was my fellow creatures. In this they were without mercy. I remember little or nothing of these lectures. I cannot have understood a great deal. But I seem to have retained certain descriptions, in spite of myself. They 
gave me courses on love, on intelligence, most precious, most precious. They also taught me to count, and even to reason. Some of this rubbish has come in handy on occasions, I don't deny it, on occasions which would never have arisen if they left me in peace (Beckett, 1979, p. 273).

Although some might read such words as nonsense or even cynical, they have the effect of deflating grandiose claims of the impact of education in order to return us to reflection upon what matters in life. This comes to pass without self-indulgence, self-hatred, pessimism or delusion, allowing us to be rather more circumspect about what we educators do. It reminds us that little of the knowledge transmitted to students, even with vigour, passion and enthusiasm, is digested or assimilated, but that ideas seep through nonetheless, and playing with them can be rather enjoyable. So much of what Beckett writes underlines the bleakness and futility of human existence. The expectation that we could ever escape this suffering serves only to compound it. Still, what I find most moving in his characters is they persist in spite of this, and as they do they find small comforts, decency and camaraderie. Perhaps this is as much as we can hope for.

\section{AN ANTI-HEROIC CURRICULUM}

Rather than seeking to eliminate failure, it is more interesting to think about how the concept of failure could be reimagined if, as Beckett suggests, failure is not accompanied by disappointment but became simply what we $d o$, rather than being something we are. It might afford a greater capacity to discern which kinds of failure are preferable and why we seem incapable of acknowledging the futility of many of the ways in which lives are spent, or expended. Failure is inevitable in practices that remain open to the world, through which the 'unknown' is allowed breathing space rather than resisted in an endless quest to master, confine and navigate the terrain of the known. For Beckett, failure is just part of what it is to be human and what matters is that one persists without seeking sanctuary in the hope of future salvation, transcendent or worldly. If we are closed to the possibility of failure, then we are closed to life's openness and unpredictability: we make of ourselves impermeable gods. Looking at failure in this light is not simply a matter of making the rather obvious statement that even when we set goals for ourselves (goals which can often be, in Beckett's view, rather unreflective and pointless), these are often frustrated or interrupted. More importantly, it asks us to question the ethics of those who refuse to countenance failure, seeking control and/or justifying success in their chosen sphere at any cost. In this respect, Beckett asks us who we become if we refuse to allow failure into our lives. However, he is not suggesting that we should seek out failure or despair; we should take comfort where we can and find solace in such happiness that comes into our lives. Krapp, in Krapp's Last Tape, only retrospectively understands the significance of his moment of happiness, but he does not live in regret: 
Past midnight. Never knew such silence. The earth might be uninhabited.

Pause.

Here I end this reel. Box_(pause)—three, spool_(pause)-five. (Pause.) Perhaps my best years are gone. When there was a chance of happiness. But I wouldn't want them back. Not with the fire in me now. No, I wouldn't want them back (Beckett, 1994a, p. 22).

Ruth Cigman (2001, and this issue) has argued that the question is not whether one should seek happiness but rather how we should do so. How we go about living also matters for Beckett. Although he would not have such confidence in the possibility of happiness, his writings bring us to ask ourselves not only why we have certain aims, but also how we attain such aims. Those who find their desires and objectives are seldom frustrated are viewed with some suspicion, as they tend, in his view, to be indifferent to the effects of their actions on the lives of others and the earth: capitalism is consummately tyrannical in its indifference to the lives of others. Such people readily find ways of explaining away their cruelty or indifference. This is not to suggest that we might have a perfect state of affairs were people to become more enlightened, but the world might become a little less brutal were we to face reality and face humanity.

In his book Simone Weil and the Intellect of Grace, Henry Finch comments on the continuation of a Roman legacy in education systems populated, broadly speaking, by heroes; even the under-trodden in the stories of the curriculum overcome in their own way, and those who do not are to be pitied or given charity. Sharon Todd observes that:

[t]he idea that education can ameliorate certain global conditions under the sign of humanity is a worrying proposition, not least because it fails to recognize that the very injustices and antagonisms which are the targets of such education are created and sustained precisely through our human talent for producing them (2010, p. 9).

We tend to promote a broadly positive and hopeful idea of humanity in education. Beckett's writings prompt consideration of some of the ways in which reimagined curricula might introduce a more gentle and minimal set of principles, evocative of a politics of decency rather than one of flourishing. Whilst there is an understandable desire to see the next generation as the one capable of resolving the horrors of the world, perhaps it might be more helpful to children and students were there to be more honest descriptions about the state of the world and the prospects for most human lives. Curricular stories could describe anti-heroes like Beckett's characters, who are tramps, refugees, clowns, psychiatric patients and denizens-those usually made invisible or set to the margins of systems-in a way that avoids presenting people as objects of pity in need of welfare or moral transformation or, perhaps worse, as exotic outsiders, since such approaches tend to consolidate the role of agency with the 'privileged'. 
Unfortunately, benevolent gestures can unwittingly serve to reinforce hierarchical relationships, creating a feeling of self-satisfaction on the part of the benefactor whilst making of the beneficiary an object of pity.

How one responds to the one who has nothing, reveals who one is. How one responds to having nothing also reveals something of oneself. But unlike fairy stories, there is no moment of redemption or transformation at the end of the stories. In the Trilogy, Molloy rejects gestures of pity and charity with vehemence.

Let me tell you this, when social workers offer you, free, gratis and for nothing, something to hinder you from swooning, which with them is an obsession, it is useless to recoil, they will pursue you to the ends of the earth, the vomitory in their hands. The Salvation Army is no better. Against the charitable gesture there is no defence that I know of. You sink your head, you put out your hands all trembling and twined together and you say, Thank you, thank you lady, thank you kind lady (Beckett, 1979, p. 38).

Unfortunately, it is easy to be blind to one's motivations and to the secret pleasures that arise through pity and charity rather than compassion. Gestures of benevolence can reinforce the ways in which another is seen (and sees himself or herself as lesser, depending on how much power one holds in a given situation).

Of the desire for prestige and the power that accompanies such gestures, Finch writes that, '.. prestige like everything illusory, is based on imagination. It is the imagination that gives people the fascinating power to seem more than human, enabling them to treat with contempt the nobodies beneath them who accept this treatment with pleasure' (1999, p. $65)$. The most reliable ways of securing prestige are fear, cruelty and terror, which can take more or less evident form. In cultures that see themselves as meritocratic, failure to conform or attain the 'goods' of 'recognition', 'agency' or 'material well-being' (to put a more acceptable gloss on prestige, power, or money) can mean that one is seen or sees oneself as individually blameworthy. However, there remain those, like Beckett, who simply refuse to accept that these constitute the goods of a human life. He does not see 'lessness' as a matter for moral condemnation or solicitude, and he does not presume that those who have power are to be envied.

\section{THE IDOLS OF PRESTIGE, PROGRESS AND PERFECTION}

The confusion is not my invention. We cannot listen to a conversation for five minutes without being acutely aware of the confusion. It is all around us and our only chance now is to let it in. The only chance of renovation is to open our eyes and see the mess. It is not a mess you can make sense of (Beckett quoted in Driver, 1961, p. 22). 
Beckett's writings offer an honest, if devastating, commitment to the surgical excision of any remnants of delusions, illusions, utopias, salvific narratives or ideals that might give false comfort to a human life. He strives to articulate an ethical position that, rather than taking refuge in speculation about how the world ought to be, helps human beings to respond courageously to how things are-_how it is', as he writes. This is described well by John Calder who says, 'The presence of evil cannot be denied. The most casual look around reveals it everywhere, it is always in a dominating position and the most that can be done by those endowed with moral instincts is to combat it, under duress, with every possible sacrifice and personal inconvenience' (2001, p. 41). He argues that the message of Beckett's work is 'in saying to as much of humanity as will listen, that if it learns to forgo personal ambition and think in terms of cooperation, compassion and companionship, it will be happier' (2001, p. 138). Whether or not Calder is correct in his analysis, it serves as an interesting provocation to those of us working and participating in systems of education. It moves one to ask what effect the principle of competition has on the experience of education, to what extent the control mechanisms of an administered society affect relationships to failure, and, whether what Sarah Ahmed (2010) describes in The Promise of Happiness as the normalising injunction to be happy forecloses or brackets the affective complexity which is constitutive of a human life. Some will suggest that concern with what others think of us can serve to motivate ethical action, yet one could counter that the mere existence of another human being demands a response of kindness, decency, civility and care, whatever that person may think of us. Indeed, a supererogatory ethic would not require recognition for such gestures.

We are thus invited to think of failure as an inevitable dimension of being human in the world to which our response is simply to persist. This clear-sighted realism seeks to see things as they are, rather than always hoping for a better world and imagining better human beings. Any betterment that arises is singular and often temporary, involving small efforts to alleviate suffering where it is witnessed, rather than the construction of grand projects of social engineering. Beckett's writings challenge and draw to light the corrosive effect of some of the fundamental aims and assumptions shaping educational practice and policy, in particular, as I have indicated, the principle of competition and the quest for prestige, in respect of which liberalism and libertarianism maintain an agnostic position. Instead of flourishing or even autonomy, a more measured, more gentle and renunciative approach to education and to life is suggested. This is does not mean a life of unabated despair: life involves many moments, some of absurdity and curiosity, others provoked by experiences of the joys of memory, the open skies and muddy landscapes. A so-called 'successful' life can be impoverished and insensible. For some it will seem heretical to rail against the idols of progress, perfection and production that have come to mark social relations in contemporary liberal democratic capitalist societies: a brief glance at many course descriptions, curricular principles, mission statements, and 'philosophies' of educational institutions reveal 
that perfectionist, progressive and aspirational discourses continue to define implicitly and explicitly the way in which humanity is understood in education, whilst the emphasis on competence and measurable outcomes underscore that what matters is success measured against standards. Given the de facto use of bell curves in many courses, it is peculiar that little attention is given to the impossibility of universal success. This is not to say that all should pass examinations, but rather that we should be more truthful about the prospects of failure and more circumspect about their functionmany of my first year students write in their philosophy essays of how they now dread thinking because of the way in which the need for success in examinations over-determined and distorted their experiences of learning. Some forms of assessment are valuable whilst others undermine the relationship to education. I also see this in prison where many of the men with whom I work failed to meet the required national standards in schools, and thus felt themselves to be failures. Children see through all of this quite quickly once they enter school. To question such aspirations can appear both obtuse and wrong-headed. Surely we ought to encourage the growth, autonomy, achievement and flourishing of children and young people in education? However, competition rooted in comparison contributes to a way of relating to failure that understands it in terms of one's being and one's failure to match up to others.

\section{FEELING LIKE A FAILURE}

The relationship to failure raises a range of questions in respect of both students' self-conceptualisation and their relation to their peers, to those in authority and to societal norms. If the dominant way of understanding failure in education is to judge success in relation to a standard or norm, then failure is a relative term contingent upon what that standard or norm prescribes. Failure understood in relation to success itself presupposes that there be a standard to serve as a benchmark, be it conventional, statistical and/or artificial. One compares oneself with others in that process. The principle of competition determines how and whether one matches up that standard and to one's peers. However, it is not inevitable that failure be understood from within an economy of comparison or competition. One might think from the perspective of failure and incompetence, emphasising not outcome but process. Certain ways of failing can be helpful and useful (although, of course, others are not, such as moral or ethical failure). Failure can be uncoupled from judgement and expectation, and the relationship between failure and experimentation in contemporary art practice, as we will see below, helps us to understand better how. This raises the question of whether practices and institutions of education need to be reimagined in order to bracket conventional understandings of success, so that failure might come to be understood not as being a failure and as a deficit of being - a relatively new concept according to Scott Sandage (2010) - but in terms of the activity of failing. This is not to make failure the telos of one's actions, which would return it to the framework of 
success, but rather invites us to think about failure and incompetence in terms of experimentation and the 'trying things out' that is immanent to any practice. This might serve as a counter-balance to those discourses that emphasise success or happiness. Might a counter-narrative to that of autonomy, agency, productivity and flourishing make a difference to students' self-understanding, relationships with others and relationship with failure? John Calder suggests that,

[a] service that Beckett has done for many is to take away their fear of inadequacy. The pressure of education, of parents, and of society itself to be successful, an achiever, a person of means and power, is always great. The purpose of such ambition can only be itself. ... The very effort of achieving something in the world tends to inhibit the ability to ask why and any desire to find a meaning or purpose to the effort, other than self-aggrandisement (2001, p. 138).

Calder perhaps over-states matters in speaking of self-aggrandisement, but it allows us to reflect upon the goods of a human life, and the values that ought underpin it, however he is right in pointing to students' fear of inadequacy. One form of resistance commonly exercised by students is silence, but what causes this? When I asked my students, who continued to remain resolutely silent in tutorials on critical thinking, why students don't participate, they spoke of a familiar litany of reasons: fear, lack of confidence, fear of looking stupid, fear of getting it wrong, fear of failure. However, a propensity to focus on the psychological dimensions of fear tends to occlude a broader political, social, economic or cultural analysis of the desire for success, mastery and competence and the correlative fear of failure in the lived experience of everyday life. One of the problems facing my students is that they had come to understand failure solely in ontological terms, construed through the language of identity as a noun, as something one is, rather than as a verb, as something one does. This is not to suggest, as behavioural psychology sometimes does, that one's actions and one's being are separate-there are times at which our failures, be it through action or inaction, strikes painfully at the heart of who we feel we are. However, students in classrooms will rarely have done something to merit such self-approbation and shame, yet still they view failure in terms of their identities. If failure is construed in ontological terms, and if enquiry into the conditions for and consequences of this relationship to failure is lacking, this can lead to quasi-behavioural reactions to perceived failure or the possibility of failure: the slightest hint of being lacking in some way can bring students to experience affective responses that are part of the same family of social affects that includes shame, embarrassment and humiliation. This is instructive. Although not an affect itself, these affects that are associated with the experience of the fear of failure, rather than necessarily failure itself, are social affects; that is, they are precipitated by the (anticipated) judgement of the other or the failure to meet a perceived standard.

This is a delicate area. There are areas in life in which we might be said to be lacking in our relation to others through indifference, insensitivity, 
cruelty or ambition. There are times when we rightfully feel ashamed because we have fallen short of our values. Shame reveals to us that our lives are bound up with those of others; however, shame becomes pernicious when the anticipated response of others operates in such a way as to preclude us from living honestly and in accordance with our values. A comparative culture that sees the path to human flourishing as one premised upon an ideology of competition is the culture of contemporary capitalism. However, despite the emphasis on success for all, it is the failure to be successful in the terms dictated by society that is the dominant tenor of life in contemporary capitalist, liberal society. Bare refusals to participate in such an economy could help to interrupt the dominant logic of contemporary capital premised on such a principle of competition. This is why, says Calder, 'His [Beckett's] many written statements on the folly of ambition and the irrelevance of failure to anything real are among his most potent and comforting, because they help to remove a major anxiety. There is neither fault nor shame in failure' (2001, p. 9), adding, '[h]is selfidentification is always with the victim' (2001, p. 106). Calder's keen observation that failure is irrelevant to anything real in Beckett is an important one, yet, of course, Beckett is acutely aware that often we fail to live a life that is ethical, and this is not a form of failure that is irrelevant.

\section{FEAR OF FAILURE}

Yes, I once took an interest in astronomy. I don't deny it. Then it was geology that killed a few years for me. The next pain in the balls was anthropology and the other disciplines, such as psychiatry, that are connected with it, disconnected and then connected again, according to their latest discoveries. What I liked in anthropology was its inexhaustible faculty of negation, its relentless definition of man, as though he were no better than God, In terms of what he is not. But my ideas on this subject were always horribly confused for my knowledge of men was scant and the meaning of being beyond me (Beckett, 1979, p. 38).

Beckett's wry descriptions of education, through the voices of his characters, offer a rather more circumspect and modest vision of education and its achievements. Yet, Molloy, Worm and Moran's reflections are not traversed by fear, but only by mild confusion and occasional over-identification with those purported aims. They seem a far cry from John Holt's descriptions of children in his classic text How Children Fail. Holt's descriptions of the experiences of children in schools are resonant with the experiences of my students in teacher education, both as students and as student-teachers. Failure in schools, as elsewhere, is understood in relation to the perceived judgement of others. For many, schooldays constitute a period of unrelenting failure to match the expectations of the teacher, the standards of the national curriculum, and the knowledge of one's peers. Oddly, a fear of failure affects even those deemed most competent and apparently success- 
ful within the educational system. Thus, the other becomes, not one on whom I may depend or who may depend on me, or someone in relation with whom I may come to constitute myself, but simply a generic marker indicating my relative success or failure.

I suggest that it is not failure per se that precipitates a feeling of humiliation, shame or fear, but anticipated judgement: not being able to do something should not necessarily elicit the fear, shame, deference, ambition and paralysis that have come to be associated with the prospect of failure. In a set of diary entries, Holt considers the relationship to failure held by the children in his classes. Schools cultivate, in his view, producers, rather than thinkers. Producers look for the right answer, certainty and approval and become concerned if they do not receive affirmation or if they get the wrong answer. Holt wonders about the responses of children to the prospect of failure. 'Kids often resist understanding, make no effort to understand, but they don't often grasp an idea and then throw it away. . . Can a child have a vested interest in failure?' (Holt, 1964, p. 19). Rather than face the prospect of getting a wrong answer, they disengage: 'The child must be right. She cannot bear to be wrong, or even to imagine that she might be wrong. When she is wrong, as she often is, the only thing to do is to forget it as quickly as possible' (1964, p. 27); or they panic: 'She closes her eyes and makes a dash for it, like someone running past a graveyard on a dark night. No looking back afterwards, either' (1964, p. 24).

Holt writes of one child, 'She also knows the teacher's strategy of asking questions of students who seem confused or not paying attention. She therefore feels safe waving her hand in the air, as if she were bursting to tell the answer' (1964, p. 27). Holt calls one strategy 'guess and look', that is, try to figure out from bodily and vocal cues the answer the teacher wants. Teachers themselves can become so obsessed with their right answer that they fail to hear the response of the child, intelligent as it may be. Describing the tenor of classroom life, he says,

Their attention depended on what was going on in class. Any raising of the emotional temperature made them prick up their ears. If an argument was going on, or someone was in trouble, or someone was being laughed at for a foolish answer, they took notice. Or if you were explaining something so simple that all the rest knew it, they would wave their arms and give agonized, half-suppressed cries of O-O-O-Oo-oh!' [. . .] But most of the time, when explaining, questioning or discussing was going on, the majority of children paid little attention or none at all (1964, p. 35).

(Even though fifty years have passed since Holt's book was published, many people currently working in teacher education who are accustomed to supervision in primary schools will be as familiar as he was with those half-suppressed cries in certain schools.) The complicated relationship between teaching and the children's experience of, relationship to, and attempts to avoid failure is traced through these descriptions. A further 
difficulty compounds matters - the teacher's self-image, hopes and desires. Holt writes, 'The conscientious teacher thinks of himself as taking his students (at least part way) on a journey to some glorious destination, well worth the pains of the trip' (1964, p. 36), however this was not how children understood school and learning. They felt that they were in school because they had to be. They had no real idea of where they were going, or why, but they knew that they had to complete the tasks set before them if they wished to avoid trouble.

Holt portrays the lived experience of children in visceral terms claiming that many children are scared most of the time in schools, even those schools that are kindest and gentlest, saying to witness the behaviour of some children is akin to an animal fleeing danger. He asks us to pay attention to the expressions on children's faces, the way that they turn to observe one another, and their bodily comportment when he remarks, 'Now it begins to look as if the expectation and fear of failure, if strong enough, may lead children to act and think in a special way' (1964, p. 39). Part of the difficulty lies in the constant expectation of success, a culture that values right answers rather than process, and behavioural management strategies that do not acknowledge the child's natural curiosity and desire to learn but that are premised on the idea that children need to be coerced into learning. Holt feels that we put children under intolerable and constant pressure to meet predetermined standards and to match the abilities of their peers. In response to this he proposes a thought experiment for teachers. 'But suppose every teacher in the school were told he had to do ten pages of addition problems, within a given time limit and with no mistakes, or lose his job' (1964, p. 52).

Another dimension to the problem is the broader cultural relationship to failure that conceives it in the ontological terms outlined above, whereby failure is seen as revelatory of the inadequacy of the self. Holt acknowledges this whilst wondering why this is the case, 'Of course, we adults tend to see all small, specific failures, of our own or of children, as proof of general failure, incompetence, worthlessness. Is it a cultural matter? Are there no people in the world for whom it is not a disgrace to do something badly?' (1964, p. 59). Even strategies of praise and affirmation can unintentionally serve to exacerbate feelings of worthlessness, in particular when encouragement to meet the 'self-concept' attributed to one has been confounded. Rather than being an instance of failing, it constitutes a failure of being. It is perhaps for this reason that 'The strategies of most of these kids have been consistently self-centred, self-protective, aimed above all else at avoiding trouble, embarrassment, punishment, disapproval or loss of status' (1964, p. 59); this is similar to the list of the reasons offered to me when I asked my students why they did not speak in tutorials. As Holt recognises this is debilitating in many ways, including for thinking: there is a difference between the figure of the 'idiot', like Molloy, who refuses to know what 'everyone knows', and the scattered, panicked response to the invitation to thinking and living outlined in the above quotations. A further danger is that children come to develop a particular relation to authority that conceives of it in terms of control, coming to desire the approval of the 
Master or the Other, who may present himself or herself, as Britzman (2006) argues, as a being without vulnerability, averse to risk, wholly adequate, godlike, wholly rational, without prejudice, and without fear. This image of autonomy without dependency is a powerful one in education, as Rachel Jones, in this issue, underlines. This is compounded by the confusion that teachers make between good character and good behaviour-good character may require contesting authority and going against the grain, and such gestures by children often meet with hostility and punishment by teachers.

The consequence of this is put starkly by Holt, 'We destroy this capacity above all by making them afraid, afraid of not doing what people want, of not pleasing, of making mistakes, of failing, of being wrong. Thus we make them afraid to gamble, afraid to experiment, afraid to try the difficult and the unknown. Even when we do not create children's fears, when they come to us with fears ready-made and built-in, we use these fears as handles to manipulate them and get them to do what we want' (1964, p. 165). This, I suggest, leads to the translation of failure of doing into failure of being. Why is it seen as a failure of one's being to be unable to do something?

\section{I'LL GO ON}

Certain of Molloy's pious statements resonate rather uncomfortably with Holt's observations. He says,

I have only to be told what good behaviour is and I am well behaved within the limits of my physical possibilities. And so I have never ceased to improve, from this point of view, for I used to be intelligent and quick. As far as good will is concerned, I had it to overflowing, the exasperated good will of the over-anxious ... And if I have always behaved like a pig, the fault lies not with me but with my superiors, who correct me only on points of detail instead of showing me the essence of the system, after the manner of the great English schools, and the guiding principles of good manner, and how to proceed, without going wrong, from the former to the latter, and how to trace back to its ultimate source a given comportment (Beckett, 1979, p. 25).

Molloy does his best to respond to cues but he doesn't really understand the point of it all. Indeed, Beckett's characters never quite fit, nor do they know what to do, but, unlike most of the children described by Holt, they are not weighed down by a sense of inadequacy born of comparison with others: being adequate or inadequate is scarcely an issue for them.

Let us briefly imagine what education might be like if our relationship to failure were to be reimagined. What if educational institutions were spaces in which we tried things out? What if they were an exercise in 'infancy', perpetual beginning, exposure and searching curiosity, as Rachel Jones, in 
this issue, describes. This does not imply a lack of persistence, diligence, attention, or that we would never complete anything (completion and success are not equivalent terms) but it means we might be liberated from the forms of judgement that paralyse agency, and it might permit poetic ruptures with cynicism and even a heightened awareness of the subtleties of the 'everyday'. A cue could be taken from contemporary artists like Francis Alÿs. Alÿs engages in acts that are often impossible, futile or useless, such as seeing how long he can wander with a $9 \mathrm{~mm}$ pistol in his hand through Mexico City before being arrested, or spending nine hours pushing an ice block through city streets until it melts, or deploying a group of five hundred volunteers to use shovels to move a sand dune four inches. These exercises allow for a poetic disruption of the everyday, and can also serve to reveal the reality of many of our working activities. Ignoring the imperative of efficiency, Alÿs scrawls axioms such as 'Maximum effort Minimum result' in his notebooks. Mark Godfrey referring to his ice-block pushing, writes, 'Here for the first time, the artist dramatized the aphorism that "sometimes doing something leads to nothing", expending maximum energy with minimum results. The action reflected on the everyday pursuits of all those working in the streets around him, and more generally on the vanity of the modernising efforts of successive Latin-American governments' (Godfrey and Biesenbach, 2010, p. 18). The axiom of 'maximum effort minimum result' does not so much prescribe as describe in a way that also forces Western culture, with its emphasis on productivity and efficiency, what, with all our efforts, are we really doing? Do we have anything to show for it all? Alÿs's works have the same kind of effect as Beckett's characters-the uselessness of their actions can serve as a hiatus provoking a distance from the immediate situation in which it seems obvious what must do and who one must be. We are forced us to ask ourselves why we assume our own actions have greater value than those of Murphy or Molloy.

The fear of failure experienced by my students and those described by Holt presupposed the possibility of being adequate and even successful. A wilful blindness to the fact that not everyone can be 'winners', 'heroes', 'achievers' or even 'all they can be' persists, and there is insufficient questioning at a policy level about which aspirations ought to be valued, or whether they are even desirable. To what extent is an honest contemplation of the human condition permitted in schools or colleges? A relationship to failure is shaped through systems of assessment that rely on benchmarks and standards, by standardised testing such as PISA, and by cultures in schools and universities that reward success and differentiate students through high stakes testing. This is not to suggest that an alternative would be the kind of 'entrepreneurial' culture increasingly promoted by businesses seeking to intervene in educational life, as this also sets its sights on success and ignores the inevitable hierarchy that emerges. Is there another way of imagining the human condition that might allow for a more subdued, nuanced and kinder philosophy of education? This is particularly important when educating future teachers whose own fears and standards may forbid the kinds of open experimentation and play with children 
that can invite critical enquiry, curiosity and exploration, as well varying material engagements through practice in different disciplines. We could learn from the ways that young children explore the world and bring some of that attentiveness, interest and absorption into our own relationships with the everyday.

A preliminary sketch of a Beckettian philosophy of education might include the following: we are inadequate, but we muddle through; the world is a mess, but we should face our situation with courage; education will not change much, but for all that, it is often an enjoyable distraction; we should be decent to other human beings, forgoing personal ambition and the desire for prestige; there is no ultimate telos to a human life, but still we persist, on; and we should try things out, experiment, without undue concern about success or failure. Perhaps then experiences of education might be more tolerable. Perhaps. Rather than experiencing oneself as a failure, one fails, fails again, fails better, fails worse.

Correspondence: Aislinn O'Donnell, Faculty of Education, Mary Immaculate College, University of Limerick, Mary Immaculate College, South Circular Road, Limerick, Ireland.

Email: aislinn.odonnell@mic.ul.ie

\section{NOTES}

1. I think here of Bruce Naumann, Fischli and Weiss, Francis Alÿs, Thomas Hirschhorn or Fluxus who try and tried to undermine a desire for control, mastery or autonomy, welcoming more gentleness, humour, weakness or experimentation in both their work and in the relationship cultivated with those encountering, or participating in, the work.

2. Whilst I acknowledge that there is an extensive literature on failure and education, one contribution that Beckett makes is to help us to understand failure as part of the human condition. This is, in part, why he and others of his generation are so critical of the administered society that seeks to eliminate risk. This is a different point to the one made by writers like Melanie Philips who challenges the idea that no one should fail. Similar criticism have been made in special needs education. The normative position that no one should fail, fails to acknowledge the reality that we do fail, and in many different ways. Children understand condescension. Conversely, there is a good deal of literature that focuses on the effort to eliminate failure because of its effects on self-esteem. However, perhaps, the real problem is learning how to fail. This is not to advocate an acquiescent position that accepts under-resourced classrooms, poor treatment of children, and so forth. This would constitute a kind of moral or ethical failure which Beckett deplores, but it is to explore a way of looking at failure that has perhaps not been sufficiently explored in the literature.

\section{REFERENCES}

Ahmed, S. (2010) The Promise of Happiness (Durham, NC, Duke University Press).

Beckett, S. (1979) The Beckett Trilogy: Molly, Malone Dies, The Unnamable (London, Picador).

Beckett, S. (1983) Worstward Ho (London, Calder).

Beckett, S. (1994a) Krapp's Last Tape and Other Dramatic Works (New York, Grove Press).

Beckett, S. (1994b) Mercier and Camier (New York, Grove Press).

Beckett, S. (2006) Waiting for Godot (London, Faber \& Faber).

Britzman, D. (2006) Novel Education: Psychoanalytical Studies of Learning and Not Learning

(New York, Peter Lang). 
Calder, J. (2001) The Philosophy of Samuel Beckett (London, Calder).

Cigman, R. (2001) Self-Esteem and the Confidence to Fail, Journal of Philosophy of Education, 35.4, pp. 561-76.

Driver, T. (1961) Beckett by the Madeleine, Columbia University Forum, IV, Summer.

Finch, H. (1999) Simone Weil and the Intellect of Grace (New York, Continuum).

Godfrey, M. and K. Biesenbach (2010) Francis Alÿs: A Story of Deception (London, Tate).

Holt, J. (1964) How Children Fail (Harmondsworth, Penguin).

Sandage, S. (2010) The Invention of Failure: Interview with Sina Najati [2002], in: L. Le Feuvre (ed.) Failure (London, Whitechapel).

Todd, S. (2010) Towards an Imperfect Education: Facing Humanity, Rethinking Cosmopolitanism (Boulder, CO, Paradigm). 